\title{
Leonardite and Fertilizer Levels Influence Tomato Seedling Growth
}

\author{
A.J. Pertuit, Jr. ${ }^{1}$, Jerry B. Dudley ${ }^{2}$, and Joe E. Toler ${ }^{3}$ \\ Clemson University, Clemson, SC 29634-0375
}

Additional index words. humic acid, fulvic acid, Lycopersicon esculentum

\begin{abstract}
New Mexico-mined raw leonardite was characterized by comparing it with the International Humic Substances Society's Standard Leonardite. In the first experiment, adding as little as 1/64 leonardite (v/v) to a sand medium increased tomato [Lycopersicon esculentum (L.) Mill. 'Mountain Pride'] root and shoot growth compared with plants produced with fertilizer alone. Growth increased linearly with increasing leonardite levels, from $0 \%$ to $25 \%$; however, $50 \%$ leonardite inhibited growth. In a second experiment, leonardite alone had no effect on plant height, shoot or root fresh and dry weight, or total leaf area, but stimulated growth when combined with a complete fertilizer. Adding 1/3 leonardite (v/v) (the highest level) and a complete fertilizer increased plant height $40 \%$, total leaf area $160 \%$, shoot fresh weight $134 \%$, root fresh weight $82 \%$, shoot dry weight $133 \%$, and root dry weight $400 \%$.
\end{abstract}

Leonardite is a naturally occurring, brownblack, oxidized form of lignite coal (O'Donnel, 1973). Humic substances are a primary constituent of leonardite and can be classified into humic acid, fulvic acid, and humin depending upon their solubility in alkali and acid (Schnitzer and Khan, 1972). With adequate mineral nutrition, humic substances can promote the growth of 'Chardonnay' grapevines (Vitis vinifera L.) (Reynolds et al., 1995), cucumber plants (Cucumis sativus L.) (Rauthan and Schnitzer, 1981), corn plants (Zea mays L.) (Tan and Nopamornbodi, 1979), and tomato seedlings (Bryan, 1976). These positive effects of humic substances are often correlated with enhanced macronutrient uptake, as well as their ability to complex transition metals such as $\mathrm{Cu}, \mathrm{Zn}, \mathrm{Fe}$, and $\mathrm{Mn}$ (Chen and Aviad, 1990). In contrast, excessive concentrations of humic substances can inhibit growth (Ayuso et al., 1996; Bryan, 1976; Rauthan and Schnitzer, 1981; Reynolds et al., 1995). These inhibitory effects have been correlated with the presence of excessive ligands, which reduce micronutrient availability to plant roots (Ayuso et al., 1996; Rauthan and Schnitzer, 1981).

Exact recommendations are difficult because of variations in leonardite material, species response, and fertilizer regimes (Vaughan and Malcolm, 1985). When soil is allowed to stand in water (i.e., become well hydrated), some of its organic material becomes soluble. This material is defined as water-extractable organic carbon (WEOC) (Tao and Lin, 2000).

\footnotetext{
Received for publication 30 May 2000. Accepted for publication 25 Nov. 2000. Technical contribution No. 4662 of South Carolina Agriculture and Forestry Research System, Clemson Univ. The cost of publishing this paper was defrayed in part by the payment of page charges. Under postal regulations, this paper therefore must be hereby marked advertisement solely to indicate this fact.

${ }^{1}$ Dept. of Horticulture. E-mail address: aprtt@ clemson.edu

${ }^{2}$ Dept. of Horticulture.

${ }^{3}$ Dept. of Experimental Studies.
}

Fuehr and Sauerbek (1967) reported that low molecular weight degradation products of humus were transported into physiologically active plant parts, but humic acids were not. Apparently, humic acids increase the availability of essential elements, particularly Fe, to the plant. Schnitzer and Poast (1967) found that humic substances can have significant effects on root growth, possibly due to fulvic acid aiding in metal ion movement. Growing geranium (Pelargonium $\times$ hortorum L.H. Bailey) cuttings in leonardite solution increased root growth and proliferation (O'Donnell, 1973). By applying two different leonardite extracts, Brownell et al. (1987) increased wine grape yields by $\approx 25 \%$ and cotton (Gossypium hirsutum L.) yields by $\approx 11.2 \%$; the greatest increase in yield was obtained when the extracts were added to the soil prior to application of a foliar fertilizer spray. Leonardite additions to a loamy sand increased corn yield as well as $\mathrm{N}$ and $\mathrm{P}$ uptakes (Duplessis and MacKinzie, 1983).

Addition of leonardite might increase production of quality ornamental plants with reduced fertilizer inputs. Using tomato as a test plant, our objectives were to determine: 1) if the addition of leonardite affects growth; 2 ) if the enhanced growth resulting from the addition of fertilizer can be enhanced further by the addition of leonardite; and 3) some of the chemical and physical properties of the leonardite utilized in our experiment and that of the International Humic Substances Society's (IHSS) leonardite standard.

\section{Materials and Methods}

Leonardite characterization. To characterize the leonardite material employed in these tests, a sample of the IHSS Standard Leonardite was obtained and analyzed along with our New Mexico leonardite (Humate Resources, Edina, Minn.). To determine moisture content, a sample was weighed at room temperature, oven-dried at $105^{\circ} \mathrm{C}$ for $24 \mathrm{~h}$, then weighed. Cation exchange capac- ity (CEC) was determined by the sum of cations $\left[\mathrm{CEC}_{\text {(sum of cations) }}=\Sigma\right.$ exchangeable bases $(\mathrm{Ca}, \mathrm{Mg}, \mathrm{K}, \mathrm{Na})+$ extractable acidity]. Exchangeable bases were determined via the ammonium acetate method, and extractable acidity was measured using the barium chloride-triethanolamine method (Thomas, 1982). Total organic carbon (TOC) was determined using a Shimadzu TOC-5000 with SSM-5000 solid sample analyzer (Shimadzu Corp., Kyoto, Japan). The value obtained was multiplied by a factor of 1.724 to determine total organic matter (Schnitzer, personal communication). Humic and fulvic acids were extracted using $0.1 \mathrm{M} \mathrm{NaOH}$ and separated using $6 \mathrm{M} \mathrm{HCl}$ (Schnitzer, 1982). The TOC of each fraction was determined using a Shimadzu TOC-5000 (Shimadzu Corp.). The humic acid TOC was multiplied by a factor of 1.724 to determine total humic acid, and the fulvic acid TOC by a factor of 2.0 to determine total fulvic acid (Schnitzer, personal communication). Total $\mathrm{N}$ was released from the leonardite sample by high temperature combustion under high-purity oxygen and quantified by thermal conductivity detection (Association of Official Analytical Chemists, 1994a). Extractable P and K were determined by extraction from leonardite with ammonium citrate ( $\mathrm{pH} 7.0)$ in the presence of disodium ethylenedinitrilotetraacetic acid (EDTA) (Association of Official Analytical Chemists, 1994b), and analyzed using inductively coupled plasma emission spectrometry (ICP). Total Fe, $\mathrm{Mg}, \mathrm{Ca}, \mathrm{S}, \mathrm{Mn}, \mathrm{Cu}$, and $\mathrm{Zn}$ content were determined by digestion of leonardite samples with $\mathrm{HNO}_{3}$ and $\mathrm{H}_{2} \mathrm{O}_{2}$ (Association of Official Analytical Chemists, 1990b), and then analyzed using ICP. Acidextractable $\mathrm{B}$ content was determined using the spectrophotometric method (Association of Official Analytical Chemists, 1990a).

The amount of water-extractable fulvic acid was measured by placing $10 \mathrm{~g}$ of leonardite in $50 \mathrm{~mL}$ of distilled water. Each sample (three replicates for each day) was mechanically shaken for $1 \mathrm{~h}$ and filtered $(0.45 \mu \mathrm{m}$ pore size $)$ after either 2, 4, 8, 16, or $32 \mathrm{~d}$ in solution. Each water extract was treated with $6 \mathrm{M} \mathrm{HCl}$ to precipitate any humic acid (Schnitzer, 1982). Total fulvic acid was determined as previously mentioned. Results were analyzed using regression analysis.

Procedure. Two experiments were conducted to evaluate the vegetative growth responses obtained by the addition of raw leonardite and/or fertilizer to the coarse sand (Play Sand, Quikrete Companies, Atlanta) growing medium. 'Mountain Pride' tomato seedlings were grown in $2.08-\mathrm{L}$ pots in a greenhouse $\left(15.5^{\circ} \mathrm{C}\right.$ minimum temperature). Two paper coffee filters were placed in the bottom of each pot to prevent the growing medium from washing through the bottom holes. Water was applied until it leached through the bottom holes, and the frequency of watering was the same for all treatments. The recommended rate of $\mathrm{N}$ application to field tomatoes is $140-168 \mathrm{~kg} \cdot \mathrm{ha}^{-1}$ (Cook, n.d.); therefore, if applied, $5 \mathrm{~g}$ of granular fertilizer $(5 \mathrm{~N}-$ $4.3 \mathrm{P}-8.3 \mathrm{~K}$ ) was mixed throughout the grow- 
ing medium in each pot. The leonardite employed in these tests was from a New Mexico mine (Humate Resources, Edina, Minn.), and its texture was similar to that of laundry detergent.

Expt. 1. The first experiment was conducted to examine the effects of leonardite on growth and to provide information about potential optimal and toxic levels. Twelve plants per treatment were arranged in a randomized complete-block design with three blocks. Seeds were sown in a peat-based germination medium 18 Feb., and transplanted (treatments applied) on 8 Apr. The media used are listed in Table 4. Data were recorded at harvest (14 May), when the first fruit began to develop (some up to $1.8 \mathrm{~cm}$ in diameter).

Expt. 2. Expt. 1 revealed that leonardite at $1 / 2$ volume was toxic and best results were obtained at 1/4 volume leonardite; therefore, Expt. 2 was conducted with $1 / 3$ volume leonardite to confirm the results of Expt. 1. In this test, six plants per treatment were arranged in a randomized complete-block design with two blocks. Seeds were sown in a peat-based germination medium 29 July and transplanted (treatments applied) on 31 Aug. Treatments are listed in Table 5. Data were recorded at harvest on 7 Oct., when the first fruit began to develop.

Statistical analysis. Analysis of variance (ANOVA) was performed on the results from the experiments, and single degree-of-freedom contrasts were used to examine specific comparisons among treatment means and to evaluate polynomial relationships between plant responses and leonardite levels at $P=0.05$.

\section{Results and Discussion}

Physical and chemical properties and nutrient analysis of the New Mexico-mined leonardite were compared with those of the IHSS Standard Leonardite (Tables 1 and 2). Laboratory tests revealed that water-soluble fulvic acids were released from leonardite from both sources (Table 3). Humic acid precipitates were not formed when the $\mathrm{pH}$ of the solution was adjusted below 2. During $32 \mathrm{~d}$, the amount of water-soluble fulvic acid from the New Mexico leonardite increased slightly, but that from the standard leonardite did not. The optimal levels of fulvic acid to enhance root and shoot growth are 50 to $300 \mathrm{mg} \cdot \mathrm{L}^{-1}$ (Chen and Aviad, 1990). Calculations revealed that the volumes of leonardite that we used $(1 / 4,1 / 8$, and $1 / 16$ leonardite per volume of growing medium) could supply levels within the optimum range.

Expt. 1. Adding fertilizer to the medium increased shoot and dry weight, and further addition of leonardite, excluding the $1 / 2$ leonardite level, further stimulated growth (Table 4). Addition of 1/4 leonardite had the greatest effects, with a $24 \%$ increase in shoot dry weight and an $87 \%$ increase in root dry weight in comparison with no leonardite. However, increasing the leonardite content to $1 / 2$ inhibited growth. Similarly, negative effects following application of high levels of humic substances have been observed on shoot and root dry weight of barley (Hordeum vulgare L.) (Ayuso et al., 1996), shoot growth of 'Chardonnay' grapevines (Reynolds et al., 1995), and shoot and root dry weight of cucumber plants (Rauthan and Schnitzer, 1981). High levels of humate can reduce uptake of $\mathrm{N}$ and some micronutrients (Ayuso et al., 1996; Rauthan and Schnitzer, 1981; Tan and Nopamornbodi, 1979). Inhibition of plant growth and nutrient uptake by high humate levels appears to be caused by an excess of chelators, which reduce nutrient availability to roots (Ayuso et al., 1996).

The overall effect of addition of leonardite in our Expt. 1 was greater on root than on shoot growth, and leonardite clearly enhanced growth beyond that produced by the addition of fertilizer alone. This first experiment established the levels of leonardite that enhance tomato growth (1/64 to $1 / 4$ volume), as well as the toxic level (1/2 volume).

Expt. 2. The addition of leonardite alone (no fertilizer) did not stimulate, and actually reduced, root fresh weight (Table 5). Fertilizer alone increased both plant height and root fresh weight. When both leonardite and fertilizer were added, linear increases were observed in plant height, total leaf area, shoot and root fresh weight, and shoot and root dry weight as the concentration of leonardite increased. Additions of $1 / 3$ leonardite (the highest level) plus fertilizer increased plant height $40 \%$, total leaf area $160 \%$, shoot fresh weight $134 \%$, root fresh weight $82 \%$, shoot dry weight $133 \%$, and root dry weight $400 \%$. These results confirm those of other researchers (Ayuso

Table 1. Physical and chemical properties of International Humic Substances Society (IHSS) Standard Leonardite [bulk source Gascoyne leonardite (Gascoyne, N. Dak.) obtained from the IHSS] and New Mexico-mined leonardite (Humate Resources, Edina, Minn.).

\begin{tabular}{lcccccc}
\hline $\begin{array}{l}\text { Leonardite } \\
\text { source }\end{array}$ & $\begin{array}{c}\text { Moisture } \\
(\%)\end{array}$ & $\mathrm{pH}$ & $\begin{array}{c}\text { CEC } \\
(\mathrm{meq} / 100 \mathrm{~g})\end{array}$ & $\begin{array}{c}\text { Total organic } \\
\text { matter }(\%)\end{array}$ & $\begin{array}{c}\text { Humic acid } \\
\text { extracted }(\%)\end{array}$ & $\begin{array}{c}\text { Fulvic acid } \\
\text { extracted }(\%)\end{array}$ \\
\hline Standard & 11.85 & 3.58 & 95.51 & 65.68 & 21.44 & 0.69 \\
New Mexico & 12.41 & 4.18 & 63.78 & 27.53 & 15.99 & 0.36 \\
\hline
\end{tabular}

Table 2. Nutrient analysis of International Humic Substances Society (IHSS) Standard Leonardite [bulk source Gascoyne leonardite (Gascoyne, N. Dak.) obtained from the IHSS] and New Mexico-mined leonardite (Humate Resources, Edina, Minn.).

\begin{tabular}{lccccccccccc}
\hline \hline & \multicolumn{10}{c}{ Nutrient (\%) } \\
\cline { 2 - 12 } & $\mathrm{N}$ & $\mathrm{P}^{\mathrm{z}}$ & $\mathrm{K}^{\mathrm{z}}$ & $\mathrm{Fe}$ & $\mathrm{Mg}$ & $\mathrm{Ca}$ & $\mathrm{S}$ & $\mathrm{B}^{\mathrm{y}}$ & $\mathrm{Mn}$ & $\mathrm{Cu}$ & $\mathrm{Zn}$ \\
\hline Standard & 1.11 & 0.004 & 0.02 & 0.476 & 0.36 & 1.675 & 0.97 & 0.13 & 0.006 & $<0.002$ & 0.0011 \\
New Mexico & 1.30 & 0.008 & $\mathrm{ND}$ & 2.151 & 0.13 & 0.795 & 1.48 & 0.009 & 0.003 & $<0.002$ & 0.0096 \\
\hline
\end{tabular}

${ }^{ } \mathrm{Ammonium}$ citrate-extractable in the presence of EDTA.

${ }^{y}$ Acid-extractable.

Table 3. Amount (mg) of water-extractable fulvic acid derived from one $\mathrm{g}$ of International Humic Substances Society (IHSS) Standard Leonardite [bulk source Gascoyne leonardite (Gascoyne, N. Dak.) obtained from the IHSS] and New Mexico-mined leonardite (Humate Resources, Edina, Minn.) after 2, 4, 8, 16, and $32 \mathrm{~d}$ in solution.

\begin{tabular}{lcccccc}
\hline \hline & \multicolumn{5}{c}{ Time in solution $(\mathrm{d})$} \\
\cline { 2 - 7 } & 2 & 4 & 8 & 16 & 32 & Linear regression \\
\hline Standard & 3.108 & 3.451 & 3.187 & 3.254 & 3.435 & Ns \\
New Mexico & 0.520 & 0.510 & 0.543 & 0.565 & 0.572 & $*$ \\
\hline
\end{tabular}

Ns, ${ }^{*}$ Nonsignificant or significant at $P<0.05$, respectively.

Table 4. The effects of addition of leonardite and/or fertilizer ( $5 \mathrm{~g} 5 \mathrm{~N}-$ $4.3 \mathrm{P}-8.3 \mathrm{~K} / 2.08-\mathrm{L}$ pot) to a coarse sand growing medium on the shoot and root dry weights of tomato seedlings (Expt. 1).

\begin{tabular}{|c|c|c|c|}
\hline \multirow[b]{2}{*}{ Fertilizer } & \multirow[b]{2}{*}{ Leonardite (v/v) } & \multicolumn{2}{|c|}{ Dry wt (g) } \\
\hline & & Shoot & Root \\
\hline None & None & 2.41 & 1.04 \\
\hline+ & None & 4.63 & 1.50 \\
\hline+ & $1 / 64$ & 4.85 & 2.04 \\
\hline+ & $1 / 32$ & 4.99 & 2.02 \\
\hline+ & $1 / 16$ & 4.50 & 2.05 \\
\hline+ & $1 / 8$ & 5.39 & 2.43 \\
\hline+ & $1 / 4$ & 5.72 & 2.80 \\
\hline+ & $1 / 2$ & 1.78 & 0.53 \\
\hline \multicolumn{2}{|l|}{ Contrasts } & \multicolumn{2}{|c|}{ Probability } \\
\hline \multicolumn{2}{|c|}{$\begin{array}{l}\text { Sand vs. sand + fertilizer } \\
\text { Rate of leonardite: } 0 \text { to } 1 / 4\end{array}$} & $<0.001$ & 0.048 \\
\hline \multicolumn{2}{|c|}{ Linear response } & 0.026 & $<0.001$ \\
\hline \multicolumn{2}{|c|}{ Deviations from linear } & 0.373 & 0.306 \\
\hline \multicolumn{2}{|c|}{ None vs. $1 / 2$ leonardite } & $<0.001$ & $<0.001$ \\
\hline \multicolumn{2}{|c|}{$1 / 4$ vs. $1 / 2$ leonardite } & $<0.001$ & $<0.001$ \\
\hline
\end{tabular}


Table 5. The effects of addition of leonardite and/or fertilizer ( $5 \mathrm{~g} 5 \mathrm{~N}-4.3 \mathrm{P}-8.3 \mathrm{~K} / 2.08$ - $\mathrm{L}$ pot $)$ to a coarse sand growing medium on height, total leaf area, shoot and root fresh weights, and shoot and root dry weights of tomato seedlings (Expt. 2).

\begin{tabular}{|c|c|c|c|c|c|c|c|}
\hline \multirow[b]{2}{*}{ Fertilizer } & \multirow{2}{*}{$\begin{array}{c}\text { Leonardite } \\
(\mathrm{v} / \mathrm{v})\end{array}$} & \multirow{2}{*}{$\begin{array}{c}\text { Height } \\
(\mathrm{cm})\end{array}$} & \multirow{2}{*}{$\begin{array}{l}\text { Total leaf } \\
\text { area }\left(\mathrm{cm}^{3}\right)\end{array}$} & \multicolumn{2}{|c|}{ Fresh wt $(\mathrm{g})$} & \multicolumn{2}{|c|}{ Dry wt $(\mathrm{g})$} \\
\hline & & & & Shoot & Root & Shoot & Root \\
\hline None & None & 25.2 & 51.35 & 2.88 & 3.52 & 0.50 & 0.22 \\
\hline None & $1 / 4$ & 29.8 & 92.28 & 4.85 & 4.15 & 0.80 & 0.30 \\
\hline+ & None & 38.8 & 242.87 & 13.15 & 9.78 & 2.15 & 0.55 \\
\hline+ & $1 / 8$ & 47.6 & 379.20 & 18.46 & 11.57 & 3.27 & 0.80 \\
\hline+ & $1 / 4$ & 49.0 & 484.77 & 25.18 & 13.08 & 4.75 & 0.98 \\
\hline+ & $1 / 3$ & 54.4 & 631.75 & 30.72 & 17.83 & 5.02 & 2.75 \\
\hline \multicolumn{4}{|l|}{ Contrast } & \multicolumn{2}{|c|}{ Probability } & & \\
\hline \multicolumn{2}{|c|}{ Sand vs. sand $+1 / 4$ leonardite } & 0.374 & 0.636 & 0.696 & 0.723 & 0.807 & 0.915 \\
\hline \multicolumn{2}{|c|}{ Sand vs. sand + fertilizer } & 0.034 & 0.083 & 0.065 & 0.014 & 0.215 & 0.671 \\
\hline \multicolumn{2}{|c|}{ Fertilizer vs. $1 / 4$ leonardite } & 0.114 & 0.123 & 0.141 & 0.021 & 0.298 & 0.749 \\
\hline \multicolumn{8}{|c|}{ Rate of leonardite: 0 to $1 / 3$} \\
\hline \multicolumn{2}{|c|}{ Linear response } & 0.022 & 0.004 & 0.011 & 0.006 & 0.038 & 0.041 \\
\hline \multicolumn{2}{|c|}{ Deviations from linear } & 0.789 & 0.800 & 0.938 & 0.277 & 0.911 & 0.266 \\
\hline
\end{tabular}

et al., 1996; Rauthan and Schnitzer, 1981; Reynolds et al., 1995; Tan and Nopamornbodi, 1979), who reported that moderate levels of humic substances enhanced plant growth whereas high levels inhibited it. Although not measured, plants that responded most to leonardite had larger, darker green leaflets than those that did not respond.

Leonardite alone had no effect on plant height, total leaf area, shoot or root fresh weight, or shoot or root dry weight; however, when combined with fertilizer, as little as 1/64 leonardite $(\mathrm{v} / \mathrm{v})$ significantly increased response over the application of fertilizer alone. The most significant findings are the increases in growth that were achieved by applying both leonardite and a complete fertilizer-increases far greater than that produced by the application of fertilizer alone. Leonardite appears, then, to enhance nutrient uptake by tomato roots, possibly by increasing cation exchange capacity or acting as a chelator of both macroand micronutrients.

Further tests with various fertilizer rates and natural soil are warranted; however, tests should include detailed characterization of the materials employed so that specific recommendations can be made.

\section{Literature Cited}

Association of Official Analytical Chemists. 1990a. Method 982.01, p. 29-30. In: K. Helrich (ed.). Official methods of analysis of the association of official analytical chemists. Assn. of Offic. Analyt. Chemists Intl., Arlington, Va.

Association of Official Analytical Chemists. 1990b. Method 990.08, p. 14-17. In: K. Helrich (ed.). Changes in official methods of analysis: $1 \mathrm{st}$ supplement to the 15 th edition of official methods of analysis. Assn. of Offic. Analyt. Chemists Intl., Arlington, Va.

Association of Official Analytical Chemists. 1994a. Method 993.13,p. 227-228. In: K. Helrich (ed.) Changes in official methods of analysis: 5th supplement to the 15 th edition of official methods of analysis. Assn. of Offic. Analyt. Chemists Intl., Arlington, Va.

Association of Official Analytical Chemists. 1994b. Method 993.31, p. 228. In: K. Helrich (ed.). Changes in official methods of analysis: 5th supplement to the 15 th edition of official methods of analysis. Assn. of Offic. Analyt. Chemists Intl., Arlington, Va.

Ayuso, M.T.Hernandez, C. Garcia, and J.A. Pascual. 1996. Stimulation of barley growth and nutrient absorption by humic substances originating from various organic materials. Bioresource Technol. 57:251-257.

Bailey, L.H. and E.Z. Bailey. 1976. Hortus third. Macmillan, New York.

Brownell, J.R., G. Nordstrom, J. Marihart, and G. Jorgensen. 1987. Crop responses from two new leonardite extracts. Sci. Total Environ. 62:492499.

Bryan, H.H. 1976. Response of tomatoes to seed and seedling applications of humates and alpha-keto acids. Proc. Fla. State Hort. Soc. 89:87-90.

Cook, W.P. n.d. Commercial tomato production in South Carolina. Clemson Univ. Coop. Ext. Serv. Circ. 625 .
Chen Y. and T. Aviad. 1990. Effects of humic substances on plant growth, p. 161-186. In: P. MacCarthy, C.E. Clapp, R.L. Malcolm, and P.R. Bloom (eds.). Humic substances in soil and crop sciences: Selected readings. Amer. Soc. Agron.-Soil Sci. Soc. Amer., Madison, Wis.

Duplessis, G.L. and A.F. MacKinzie. 1983. Effect of leonardite applications on phosphorous availability and corn growth. Can. J. Soil Sci. 63:749751.

Fuehr, F. and D. Sauerbek. 1967. The uptake of colloidal organic substances by plant roots, as shown by experiments with $\mathrm{C} 14$ labeled humus compounds, p. 317-328. In: Isotopes in plant nutrition and physiology. Intl. Atomic Energy Agency, Vienna, Austria.

O'Donnel, R.W. 1973. The auxin-like effects of humic preparations from leonardite. Soil Sci. 116:106-112.

Rauthan, B.S. and M. Schnitzer. 1981. Effects of a soil fulvic acid on the growth and nutrient content of cucumber (Cucumis sativus) plants. Plant and Soil 63:491-495.

Reynolds, A.G., D.A. Wardle, B. Drought, and R. Cantwell. 1995. Gro-Mate soil amendment improves growth of greenhouse-grown 'Chardonnay' grapevines. HortScience 30:539-542.

Schnitzer, M. 1982. Organic matter characterization, p. 581-594. In: A.L. Page (ed.). Methods of soil analysis, part 2. Chemical and microbial properties, 2nd ed. Amer. Soc. Agron.-Soil Sci. Soc. Amer., Madison, Wis.

Schnitzer, M. and M.U. Khan. 1972. Humic substances in the environment. Marcel Dekker, New York.

Schnitzer, M. and P.A. Poapst. 1967. Effects of a soil humic compound on root initiation. Nature 213:598-599.

Tan, K.H. and V. Nopamornbodi. 1979. Effect of different levels of humic acids on nutrient content and growth of corn (Zea mays L.). Plant and Soil 51:283-287.

Tao, S. and B. Lin. 2000. Water soluble organic carbon and its measurement in soil and sediment. Water Res. 34:1751-1755.

Thomas, G.W. 1982. Exchangeable cations, p. 159165. In: A.L. Page (ed.). Methods of soil analysis, part 2. Chemical and microbial properties, 2nd ed. Amer. Soc. Agron.-Soil Sci. Soc. Amer., Madison, Wis.

Vaughan, D. and R.E. Malcolm. 1985. Influence of humic substances on growth and physiological processes, p. 37-75. In: D. Vaughan and R.E. Malcolm (eds.). Soil organic matter and biological activity. Martinus Nijhoff/Dr W. Junk, Dordrecht, The Netherlands. 